\title{
BM-MSCs Differentiated Insulin-Producing Cells Produce More Insulin in Presence of EGF than of FGF
}

\author{
Cheia Majeed1, Ahmed M. Al-Shammari2*, Eman H. Yausif1, Nahi Y. Yaseen², \\ Ayman Ali Husien ${ }^{2}$, Rajha A. Al-Naimi' ${ }^{1}$ Adnan Ajeel² \\ ${ }^{1}$ Department of Pathology, College of Veterinary Medicine, Baghdad University, Baghdad, Iraq \\ ${ }^{2}$ Experimental Therapy Department, Iraqi Center for Cancer and Medical Genetic Research, Al-Mustansiriya \\ University, Baghdad, Iraq \\ Email: ${ }^{*}$ ahmed.alshammari@iccmgr.org
}

Received 20 June 2015; accepted 3 September 2015; published 7 September 2015

Copyright (C) 2015 by authors and Scientific Research Publishing Inc.

This work is licensed under the Creative Commons Attribution International License (CC BY). http://creativecommons.org/licenses/by/4.0/

(c) (i) Open Access

\begin{abstract}
Adult stem cells have the ability to differentiate into islet like cells for the hope of treating diabetes mellitus (DM). The most important part is the differentiation process from naive stem cells to fully differentiated fully functional islet cells. For this purpose, we wanted to optimize the current proposed differentiation media by replacing the FGF with EGF and measure insulin production. Bone marrow-derived MSCs were from mice long bones and expanded in cell culture before induction of differentiation. Stem cells surface markers were analyzed by immunocytochemistry. Cultured stem cells were negative for CD34 while they expressed high levels of CD90. Differentiated cells morphology was studied by using H \& E stain. Differentiated cells were detected by studying protein expression of insulin as specific marker for IPC differentiation. Cells function was studied by measuring the insulin production in tissue culture supernatant in vitro and also insulin release in response to glucose challenge. Ditizone staining were both positive. Insulin was secreted by these cells in response to different concentrations of glucose stimulation in a regulated manner. Cells induced with formula contain EGF produced more insulin in the same formula but contain FGF instead, this prove that EGF is the best to use during differentiation process.
\end{abstract}

\section{Keywords}

Diabetes Mellitus, Pancreatic $\beta$ Cells, Growth Factors

\footnotetext{
"Corresponding author.
} 


\section{Introduction}

Diabetes Mellitus (DM) is a devastating disease affecting millions of people worldwide. In DM type1, destruction of pancreatic $\beta$ cells by autoimmune attack results in decrease of insulin supply which leads to hyperglycemia and related serious complications. While DM type 2 is caused by insulin resistance and leads to hyperglycemia [1] [2]. Stem cells are important sources of insulin producing cells (IPCs) because of their multiple differentiation potential. IPCs can be generated from adult stem cells [3].

Islet cell therapy (islet transplantation) is an important promising modality for diabetes therapy. Although some progress has been reported in islet transplantation, it has been hampered by immune rejection as well as by the limited availability of transplantable donor islets. On the other hand, mesenchymal stem cells possess broad differentiation ability. This has led to the investigation of the potentials of their therapeutic applications and their ability to differentiate into a number of cell types such as blood, liver, lung, skin, muscle, neuron and insulin producing cells [4]. Isolated adult mice bone marrow mesenchymal stem cells successfully induced to differentiate into insulin-producing cells. These cells had corrected the high blood glucose levels of chemically induced diabetic mice [5].

This work aimed to evaluate IPC differentiation formulas, in presence of FGF or with EGF in regard to insulin production by using adult bone marrow-derived MSCs as a source of IPCs for $\beta$-cell replacement.

\section{Materials and Methods}

\subsection{Isolation and Culture of Bone Marrow-Derived Mesenchymal Stem Cells}

Bone marrow was isolated from tibiae and femur bones of adult mice after being euthanized according to the Iraqi Center for Cancer and Medical Genetic Research guidelines and approved by animal care committee. The bones were sterilized by immersion in 70\% ethanol. The ends of the bones were cut and bone marrow was extruded by inserting a needle in one end through the bone shaft and injection of Tissue culture media (MEM, USbiological, USA) containing 10\% fetal bovine serum (FBS, Capricorn-Scientific, Germany). The effluent was collected in sterile tubes. Gentle pipetting resulted in generation of a single cell suspension. Bone marrow cells were counted and plated with a concentration of $1 \times 10^{-6} / \mathrm{ml}$ in T-25 flasks. The cells were then cultured in MEM containing $10 \% \mathrm{FBS}$ and $1 \%$ penicillin and streptomycin at $37 \mathrm{C}$ in $5 \% \mathrm{CO}_{2}$ Incubator.

\subsection{Expansion of Bone Marrow-Derived Mesenchymal Stem Cells}

After 24 hrs, the non-adherent cells were discarded. The adherent cells will be referred to as MSCs. These were fed for 7 days with complete MEM. When $80 \%$ confluence was reached as observed under inverted microscope (Olympus, Japan), the cells were washed with PBS and detached with a solution of $1 \mathrm{ml}$ of trypsin/ EDTA. Cells were resuspended with complete MEM and tissue culture flask was used, this referred to as a first passage. This step was repeated for a second passage. Each passage was completed in 5 days.

\subsection{Phenotyping of BM-MSCs}

Bone marrow-derived MSCs (passage 2) were trypsinized and cultured in tissue culture dish with cover slip inside at density of $1 \times 10^{-6}$ cells $/ \mathrm{ml}$. Cells grown on the cover slip to confluent after 3 - 4 days from the culture. Cells washed three times by PBS, dried and fixed with $4 \%$ formaldehyde for 9 - 10 minutes. Cells blocked and stained with anti-CD90 and anti-CD34 antibodies.

\subsection{Differentiation of Mesenchymal Stem Cells to Insulin-Producing Cells}

Mesenchymal stem cells (passage 2) were used for induction. After trypsinization cells were cultured at a density of $1 \times 10^{6}$ cells in $25 \mathrm{~cm}^{2}$ tissue culture flasks (Nunc, Denmark). After confluency, induction of differentiation was done by two different four steps formulas. Formula one: Step 1, the cell monolayer was treated for 24 hours with high glucose MEM (HMEM, 25 mol\Glucose) (US-biological, USA) supplemented with 10\% FBS (Capricorn, Germany) and $10^{6} \mathrm{~mol} / \mathrm{L}$ retinoic acid (Santa Cruz Biotechnology, USA); Step 2, the medium was changed to H-DMEM with only 10\% FBS for 48 hrs; Step 3, the medium was changed to low glucose Medium (LMEM), supplemented with 10\% FBS, $10 \% \mathrm{mmol} / \mathrm{L}$ nicotinamide (Santa Cruz Biotechnology, USA) and 20 $\mathrm{ng} / \mathrm{ml}$ fibroblast growth factor (US-biological, USA) for 6 days; Step 4, the low glucose medium was supple- 
ment with 10\% FBS and 10 nmol/L exenden-4 (Santa Cruz Biotechnology, USA) for 6 days. Formula 2 was similar with modification of Step 3, by adding $20 \mathrm{ng} / \mathrm{ml}$ epidermal growth factor (US-biological, USA) instead of FGF.

\subsection{DTZ Staining}

At day 15 of culture, the differentiated clusters were examined for insulin producing cells by staining with diphenylthiocarbazone (DTZ). Stock solution was prepared as previously described [6], by dissolving $10 \mathrm{mg}$ of STZ (Santa Cruz Biotechnology, USA) in $10 \mathrm{ml}$ of dimethylsulfoxide (Santa Cruz Biotechnology, USA) and stored at $-20^{\circ} \mathrm{C}$. At staining 1:10 dilution in PBS of stock solution were made and $2 \mathrm{ml}$ of dithizon were added to cultured cells. Differentiated and undifferentiated cells were incubated at $37^{\circ} \mathrm{C}$ for 30 minutes in DTZ containing medium.

\subsection{Differentiation Detection}

Cells were trypsinzed and reseeded on coverslips overnight. Cells were washed three times by PBS and fixed by 4\% formaldehyde for 9 - 10 minutes, blocked with 4\% hydrogen peroxide for 10 minutes. Serum blocking for 1 hour, and 1/100 diluted primary antibody was applied to slides, anti-insulin (Santa Cruz Biotechnology, USA) at $4^{\circ} \mathrm{C}$ overnight. Biotinylated secondary antibody was added to slides for 30 minutes in room temperature following by Avidin-HRP. After washing (DAB) reagent incubated for 5 minutes (Santa Cruz Biotechnology, USA). Hematoxylin was used as a counter stain. Finally, mounted and examined under light microscope for brown positive cells.

\subsection{Measurement of Insulin Secretion}

Insulin secretion was induced by adding low glucose (3 Mm) serum free MEM and incubated at $37^{\circ} \mathrm{C}$ for $12 \mathrm{~h}$. Cells were washed with PBS twice and high glucose $(17.5 \mathrm{Mm})$ were added and incubated at $37^{\circ} \mathrm{C}$ for $2 \mathrm{~h}$. The media were collected and stored in deep freeze $-85^{\circ} \mathrm{C}$ until measured using an insulin ELISA kit (Raybiotech, USA).

\section{Results}

\subsection{Culture and Expansion of Bone Marrow-Derived Mesenchymal Stem Cells}

The primary culture of BMSCs showed after $24 \mathrm{~h}$ a few cells attached and formed adherent cells while the nonadherent cells were discarded by the changing the culture media after $48 \mathrm{~h}$ (Figure 1(A) \& Figure 1(B)).

The adherent cells began to proliferate and grow to form a monolayer after 5 - 6 days. Stem cells morphology described as spindle with oval body and flattened ends (Figure 1(C) \& Figure 1(D)). The cells were subcultured once or twice as maximum every 5 - 7 days without visible morphologic changes (Figure 1(C) \& Figure 1(D)).

\subsection{Phenotyping of the Isolated BM-MSCs}

Immunocytochemistry revealed that these cells expressed strong signal of CD90 (Figure 2(A)) when compared to negative control (Figure 2(B)) and absence of any CD34 expression (Figure 2(C)). H \& E staining for the Bone Marrow Mesenchymal Stem cells monolayer confirm the morphological features recognized by the light microscope (Figure 2(D)).
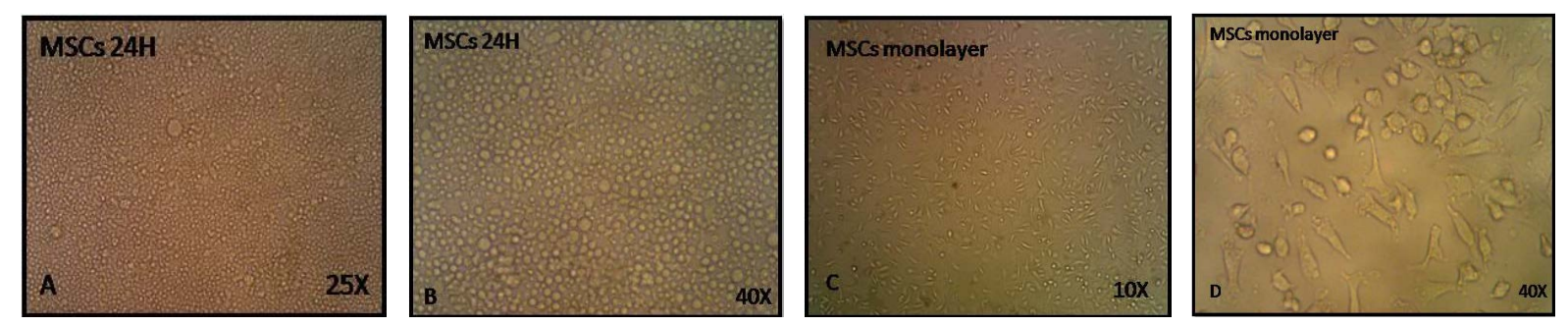

Figure 1. Morphology of undifferentiated mesenchymal stem cells, 24 after isolation (A: 25X, B: 40X) and four days after isolation (C: 10X, D: 40X) showing spindle shape fibroblast like cells. 


\subsection{Morphologic Changes and Phenotyping of Differentiated BM-MSCs}

In the formula one, changes in the number of cell aggregation were colonies shaped like islet cells with regular structure (Figure 3(G) and Figure 3(J)). However, in the formula two, the number of cells aggregation was more with regular colonies (Figure 3(K) and Figure 3(L)). Differentiation of IPC was assessed by immunocytochemistry. After end stage at 15 days from differentiation, the presence of the insulin granules within IPC cytoplasm was highly detected by presence of brown positive cells in most of the differentiated cells. Moreover, to evaluate the insulin-producing cells in cultures, we stained the differentiated cells with zinc-chelating agent (DTZ) DTZ is binding substance, and pancreatic islets are stain crimson red after DTZ treatment. Differentiated cell clusters were distinctly stained crimson red by DTZ (Figure 4).
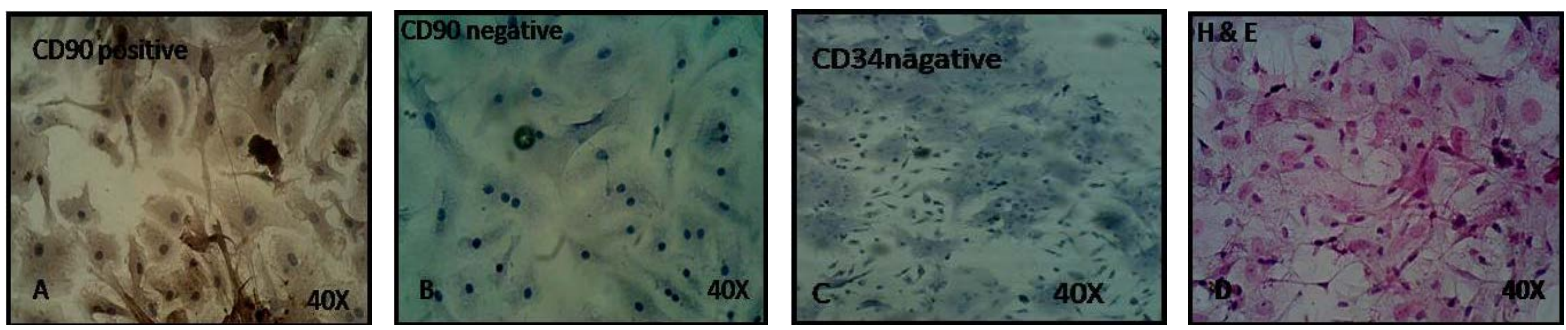

Figure 2. Immunocytochemical staining of mesenchymal stem cells for CD90 positive (A: 40X), negative (B: 40X) and CD34 negative (C: 40X) and stained with H \& E (D: 40X).
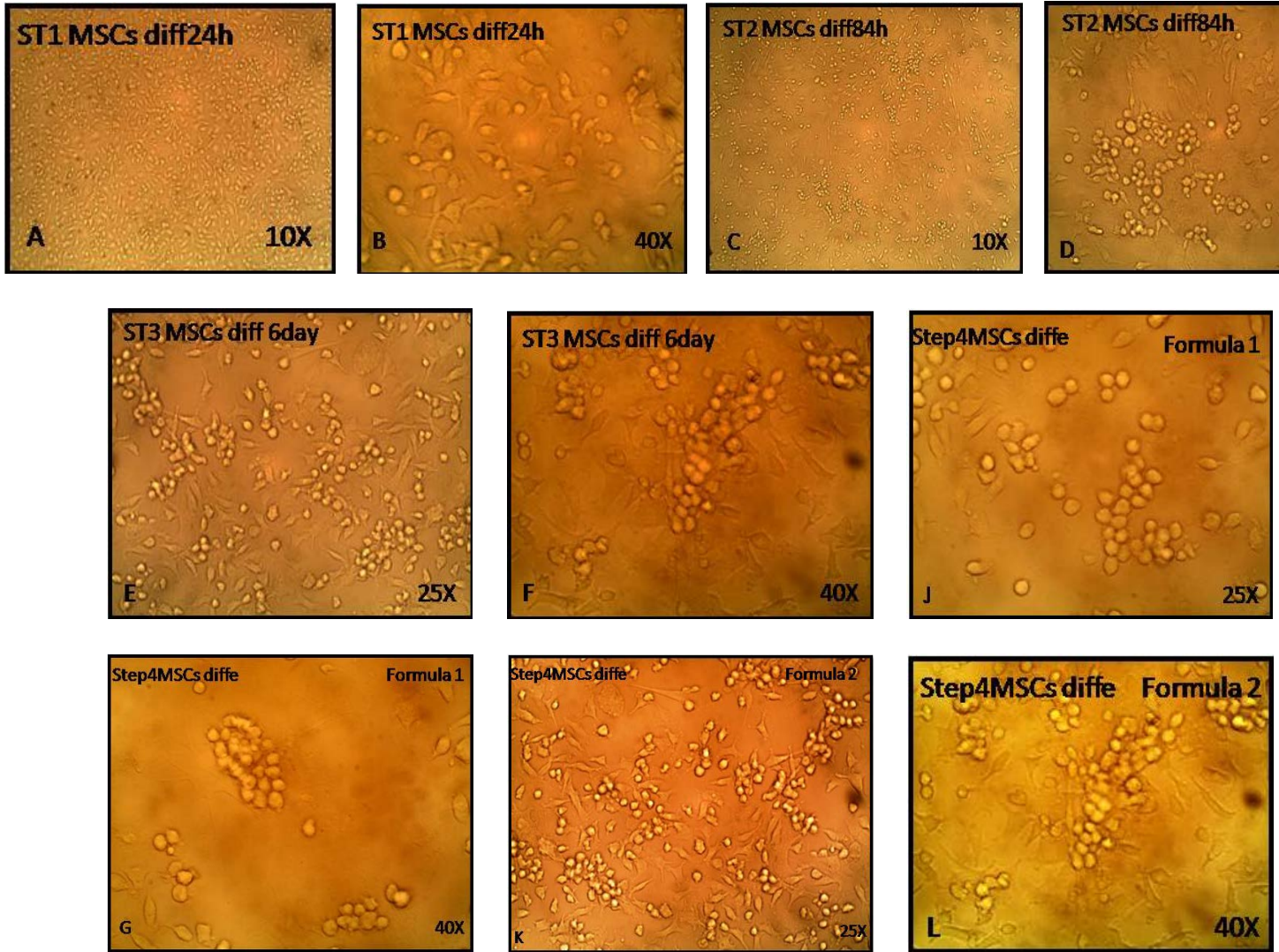

Figure 3. In vitro islet-like cells trans differentiation of BM-MSCs at passage 2 (four-steps protocol) using routine 2D culture system. Step one (A: 10X and B: 40X) cells begin to convert into round like but some cells remained spindle shape. Step 2 (Figure 3(C) and Figure 3(D)) cells begin to aggregates and intertwined together. Step 3 (Figure 3(E) and Figure 3(F)) cells begin to change into epithelial like and into round and form clusters like. Step 4 formula one (Figure 3(J) and Figure $3(\mathrm{G})$ ) and for formula two (Figure 3(K) and Figure 3(L)). In both formulas, cells begin to aggregates and intertwined together to form colonies like at 16 days as Examined under inverted microscope. 

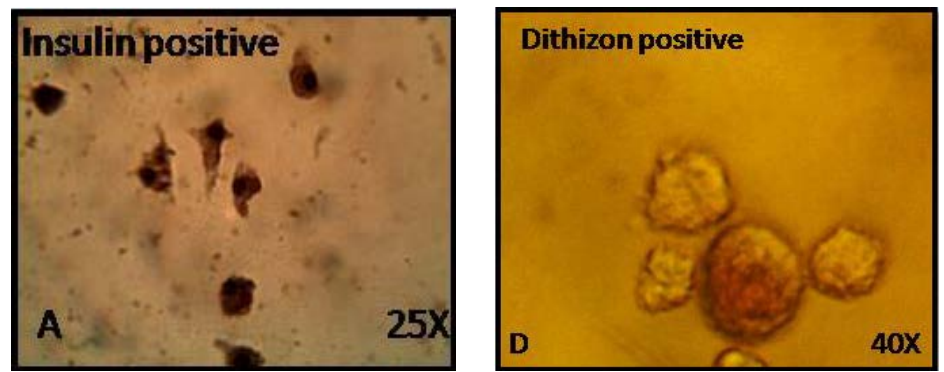

Figure 4. Immunocytochemical staining of differentiated cells for insulin (A: 25X). Differentiated cells detection with Cell clusters stained crimson red with DTZ (B: 40X) for both formula one and two where both stained positive.

\subsection{Functional Evaluation for the Differentiated Cells (Insulin Release Assay)}

Differentiated cells clusters released increasing amounts of insulin in presence of (17.5 Mm) glucose concentration. The mean insulin concentration secreted by the clusters was $(0.3803 \pm 0.002209 \mu \mathrm{IU} / \mathrm{ml})$ for formula one. However, formula two was higher $(0.4400 \pm 0.005526 \mu \mathrm{IU} / \mathrm{ml})$. These results represent the mean of this experiment; differences were statistically significant $(\mathrm{P}<0.05)$. Cultured MSCs supernatants showed very low barely detectable amount of insulin, which can be neglected $(0.004156 \pm 0.0005547 \mu \mathrm{IU} / \mathrm{ml})$.

\section{Discussion}

In our experiment, which is a preliminary study to evaluate insulin production from induced islet cells under influence of FGF and EGF. We were successful to isolate, culture and propagate mesenchymal stem cells, which were used for this evaluation. The morphological characterization of the cultured cells suggested being of stem cells in nature. We further tested the phenotype of bone marrow-derived mesenchymal stem cells and found it to be negative for CD34, which indicated they were unlikely to be hematopoietic stem cells. On the contrary, CD90 were positive indicating that the cultured bone marrow-derived cells were mesenchymal stem cells [7]. As proved by literatures, these cells were capable of generating IPCs [8] [9].

Different protocols have been tried to induce bone marrow-derived MSCs to differentiate into IPCs in vitro [8] [9]. High glucose concentration is considered as a potent inducer for pancreatic islet differentiation [10].

We tested a standard protocol [11] for IPC induction that utilized FGF as growth factor in final step and compared it to modified formula with replacing the FGF with EGF of differentiation protocol for induced BMMSCs differentiation into islet cell in vitro. This protocol was developed as four-step protocol for differentiating stem cells into islet cells [12]. Both formula one and two found to be able to induce MSCs differentiation into insulin producing cells and secreting significant amount of insulin, however, presence of EGF shown to enhance insulin production in the induced cells as measured by quantitative ELISA assay. This was a result of cells proliferation in the media contain high glucose and growth factors. These factors are essential for supporting in vitro differentiation.

Mesenchymal stem cells were cultured in glucose rich medium. Glucose is a growth factor for $\beta$-cell replication in vitro and in vivo at 20 - $30 \mathrm{~mol} / \mathrm{lm}$ concentrations. Glucose increases insulin content in cells derived from adult stem cells at a $5 \mathrm{~mol} / \mathrm{l}$ mconcentration [13]. This supports the extra energy needed for cell division [14]. Retinoic acid, increasing proliferation and differentiation of beta cells, either from ducts or from islets, may be through up regulation or down regulation of factors or genes controlling these processes [15]. Epidermal growth factor increases cells differentiation because it is essential for proliferation into islets cells [16]. Fibroblast growth factor increases cell proliferation and early stages of clustering of pancreatic precursor cells [17]. On the other hand, nicotinamide is a poly ADP-ribose synthetase inhibitor and could induce pancreatic progenitor cells into insulin producing cells [18]. Whereas exendin-4 could also stimulate both $\beta$-cell replication and neogenesisto from ductal progenitor cells and inhibit apoptosis of $\beta$-cells [19].

The induced IPCs were morphologically similar to pancreatic islet-like cells. More importantly, they not only produced insulin but also could secret insulin in response to different concentration of glucose stimulation in a regulated manner [20]. Therefore, we considered that bone marrow-derived MSCs as a good source of allograft 
for IPCs ( $\beta$ cells) replacement therapy, which could avoid immune rejection and ethical issue of embryonic origin. In conclusion, this study indicates that current published formulas can lead adult BM-MSCs to differentiate into insulin producing cells in vitro by using the four step protocol under appropriate conditions and EGF presence can enhance insulin production better than FGF as growth factor in Step 4. These results provide the strong evidence for our team to progress in testing feasibility of allograft transplantation utilizing bone marrow-derived MSCs IPC in the therapy of DM.

\section{References}

[1] Zhang, Y.H., Shen, W.Z., Hua, J.L., Lei, A.M., Lv, C.R., Wang, H.Y., Yang, C.R., Gao, Z.M. and Dou, Z.Y. (2010) Pancreatic Islet-Like Clusters from Bone Marrow Mesenchymal Stem Cells of Human First-Trimester Abortus Can Cure Streptozocin-Induced Mouse Diabetes. Rejuvenation Research, 13, 695-706. http://dx.doi.org/10.1089/rej.2009.1016

[2] Raju, S.M. and Raju, B. (2010) Illustrated Medical Biochemistry. 2nd Edition, Jaypee Brothers Medical Publishers Ltd., New Delhi.

[3] Kang, H.M., Kim, J., Park, S., Kim, J., Kim, H., Kim, K.S., et al. (2009) Insulin-Secreting Cells from Human EyelidDerived Stem Cells Alleviate Type I Diabetes in Immunecompetent Mice. Stem Cells, 27, 1999-2008.

[4] Morisot, C.F., Fraipont, D.E., Richard, M., Marchand, M., Savatier, P., Bosco, D., Favrot, M. and Benhamou, P. (2005) Human Bone Marrow Mesenchymal Stem Cell Can Express Insulin and Key Transcription Factors of the Endocrine Pancreas Developmental Pathway upon Genetic and/or Micro Environmental Manipulation in Vitro. Stem Cells, 23, 594-603. http://dx.doi.org/10.1634/stemcells.2004-0123

[5] Gabr, M., Sobh, M., Zakaria, M., Refaie, A. and Ghoneim, M. (2008) Transplantation of Insulin-Producing Clusters Derived from Adult Bone Marrow Stem Cells to Treat Diabetes in Rats. Experimental and Clinical Transplantation, 6, 236-243.

[6] Taneera, J., Rosengren, A., Renstrom, E., Nygren, J.M., Serup, P., Rorsman, P., et al. (2006) Failure of Transplanted Bone Marrow Cells to Adopt a Pancreatic $\beta$-Cells Fate. Diabetes, 55, 290-296. http://dx.doi.org/10.2337/diabetes.55.02.06.db05-1212

[7] Evans, C.M., Vestermark, G.L. and Mirmira, R.G. (2009) Development of Insulin-Producing Cells from Primitive Biologic Precursors. Current Opinion in Organ Transplantation, 14, 56-63. http://dx.doi.org/10.1097/MOT.0b013e3283186fc1

[8] Zhang, Y., Li, C.D., Jiang, X.X., Li, H.L., Tang, P.H. and Mao, N. (2004) Comparison of Mesenchymal Stem Cells from Human Placenta and Bone Marrow. Chinese Medical Journal, 117, 882-887.

[9] Yang, L., Li, S., Hatch, H., Ahrens, K., Cornelius, J.G., Petersen, B.E. and Peck, A.B. (2002) In Vitro Trans-Differentiation of Adult Hepatic Stem Cells into Pancreatic Endocrine Hormone-Producing Cells. Proceedings of the National Academy of Sciences of the United States of America, 99, 8078-8083.

[10] Guo, Z., Yang, J., Liu, X., Li, X., Hou, C., Tang, P.H., et al. (2001) Biological Features of Mesenchymal Stem Cells from Human Bone Marrow. Chinese Medical Journal, 114, 950-953.

[11] Kern, S., Eichler, H., Stoeve, J., Klular, H. and Bieback, K. (2006) Comparative Analysis of Mesenchymal Stem Cells from Bone Marrow, Umbilical Cord Blood, or Adipose Tissue. Stem Cell, 24, 1294-1301 http://dx.doi.org/10.1634/stemcells.2005-0342

[12] Soria, B., Skoudy, A. and Martín, F. (2001) From Stem Cells to Beta Cells: New Strategies in Cell Therapy of Diabetes mellitus. Diabetologia, 44, 407-415.

[13] D’Amour, K., Bang, A., Eliazer, S., Kelly, O., Aguluick, A., Smart, N., Moorman, M., Kroon, E., Carpenter, M. and Baetge, E. (2006) Production of Pancreatic Hormone-Expressing Endocrine Cells from Human Embryonic Stem Cells. Nature Biotechnology, 24, 1392-1401. http://dx.doi.org/10.1038/nbt1259

[14] Kim, Y., Lee, J., Shin, J., Kim, H. and Kim, C. (2003) Enhancement of Mouse Pancreatic Regeneration and HIT-T15 Cell Proliferation with Rat Pancreatic Extract. Biochemical and Biophysical Research Communications, 309, 528-532. http://dx.doi.org/10.1016/j.bbrc.2003.07.011

[15] Cras, M.C., Elghazi, L., Czernichow, P. and Scharfmann, R. (2001) Epidermal Growth Factor Increases Undifferentiated Pancreatic Embryonic Cells in Vitro: A Balance between Proliferation and Differentiation. Diabetes, 50, 15711579. http://dx.doi.org/10.2337/diabetes.50.7.1571

[16] Elghazi, L., Cras, M.C., Czernichow, P. and Scharfmann, R. (2002) Role for FGFR2IIIb-Mediated Signals in Controlling Pancreatic Endocrine Progenitor Cell Proliferation. Proceedings of the National Academy of Sciences of the United States of America, 99, 3884-3889. http://dx.doi.org/10.1073/pnas.062321799

[17] Kramer, B. and Penny, C. (2001) Regulation of Embryonic Chick Insulin Cells: Effect of Retinoic Acid and Insu- 
lin-Like Growth Factor 1. Cells Tissues Organs, 169, 42-48. http://dx.doi.org/10.1159/000047859

[18] Tang, D.-Q., Cao, L.-Z., Burckhardt, B., Xia, C.-Q., Litherl, S.A., Atkinson, M.A. and Yang, L.-Y. (2004) In Vivo and in Vitro Characterization of Insulin-Producing Cells Obtained from Murine Bone Marrow. Diabetes, 53, 1721-1732. http://dx.doi.org/10.2337/diabetes.53.7.1721

[19] Xu, G., Stoffers, D., Habener, J. and Bonner-Weir, S. (1999) Exendin-4 Stimulates both Beta-Cell Replication and Neogenesis, Resulting in increased Mass and Improved Glucose Tolerance in Diabetic Rats. Diabetes, 48, 2270-2276. http://dx.doi.org/10.2337/diabetes.48.12.2270

[20] Bouwens, L. and Rooman, I. (2005) Regulation of Pancreatic Beta-Cell Mass. Physiological Reviews, 85, $1255-1270$. http://dx.doi.org/10.1152/physrev.00025.2004 